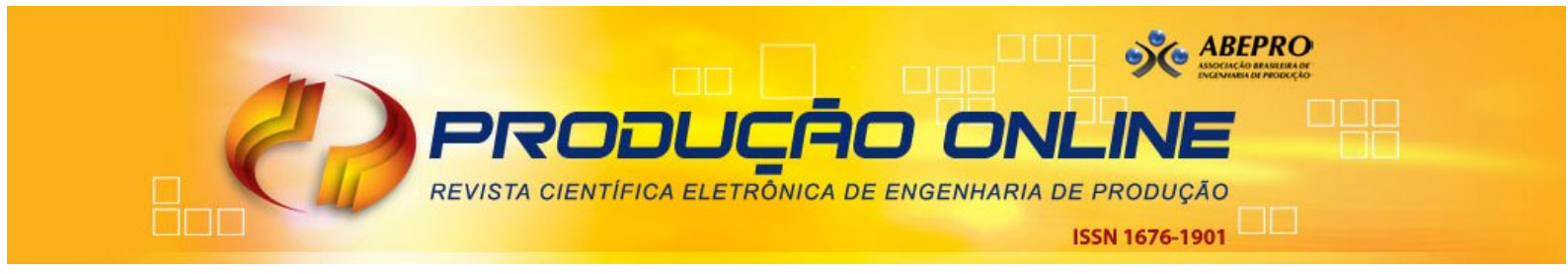

\title{
ANÁLISE DO PROCESSO PRODUTIVO DE UMA EMPRESA DO SEGMENTO DE CERÂMICA VERMELHA À LUZ DA PRODUÇÃO MAIS LIMPA
}

\section{CLEANER PRODUCTION ANALYSIS IN A COMPANY OF THE RED CERAMIC SEGMENT}

\author{
Dayanna dos Santos Costa Maciel* E-mail: dayanna-costa@hotmail.com \\ Lúcia Santana de Freitas *E-mail: luciasdefreitas@ufcg.edu.br \\ *Universidade Federal de Campina Grande (UFCG), Campina Grande, PB
}

\begin{abstract}
Resumo: O presente trabalho teve como objetivo analisar o processo produtivo de uma indústria do segmento de cerâmica vermelha à luz da Produção mais Limpa $(\mathrm{P}+\mathrm{L})$, tomando como base teórica o modelo de $P+L$ proposto pelo Centro Nacional de Tecnologias Limpas (CTNL, 2003b). Quanto à metodologia, classifica-se como exploratória e descritiva, utilizando-se do método estudo de caso. Para tanto, foram coletados dados primários e secundários, os primários foram obtidos através de entrevistas semi-estruturadas com o proprietário e gerente de produção e um questionário aplicado ao proprietário. Quanto aos dados secundários, estes foram obtidos por meio de licença ambiental da empresa, relatórios, documentos de auditorias, normas e pesquisas na web, entre outros. Como resultados foram constatados: um desperdício em torno de $10 \%$ dos produtos fabricados (tijolos, telhas e blocos); emissão de poluentes como cinzas e gases $\left(\mathrm{CO}_{2}\right)$; alto consumo de recursos naturais como argila, água, energia elétrica e lenha. Tal situação está sendo modificada em função das ações que estão adotadas para a obtenção de uma produção mais limpa.
\end{abstract}

Palavras-chave: Gestão ambiental. Produção mais Limpa. Segmento de Cerâmica Vermelha. Recursos Naturais. Impactos Ambientais.

\begin{abstract}
The present study had as objective to analyze the productive process of a red ceramic segment industry in relation to the Cleaner Production (CP), based on the theoretical model proposed by National Center of Clean Technologies (CTNL, 2003b). As for the methodology, is classified as exploratory and descriptive, using the case study method. For this purpose, data was collected primary and secondary, the primers were obtained through semi-structured interviews with the owner and manager of production and a questionnaire administered to the owner. As for the secondary data, they were obtained through the company's environmental license, reports, documents, audits, standards and web searches, among others. As results were found in a waste around $10 \%$ of manufactured products (bricks, tiles and blocks); Emission of pollutants such as ash and gases $\left(\mathrm{CO}_{2}\right)$; High consumption of natural resources such as clay, water, electricity and firewood. This situation is being modified in the function of actions which are taken to obtain a cleaner production.
\end{abstract}

Keywords: Environmental Management. Cleaner Production. Red Ceramic Segment. Natural Resources. Environmental Impacts.

\section{INTRODUÇÃO}

O ser humano utiliza inúmeros bens e produtos para atender suas diversas necessidades. Neste sentido, grande parte do que é utilizado no dia-dia é resultado 
de um processo produtivo, o qual faz uso de fatores como: recursos naturais, trabalho e capital. Neste contexto, desde o início da civilização, o homem tem aplicado seus conhecimentos para transformar um bem ou matéria-prima em outro bem com maior utilidade no seu cotidiano, nesta conjuntura, cada indivíduo era produtor de suas próprias ferramentas e de produtos necessários para a sua manutenção. Com o passar dos anos, devido ao acúmulo de conhecimento e experiência, bem como, o aumento das interações sociais, esta forma de produção artesanal passou a ter um caráter mais técnico dando surgimento à produção organizada. Essa, é resultante do processo de transformação industrial, por sua vez, acarretou o aumento dos níveis de consumo e extração dos recursos naturais, assim como o lançamento dos rejeitos de produção no meio ambiente, sem nenhuma preocupação com as consequências desta atitude.

No entanto, ao longo do tempo, atitudes que geram impacto ambiental ainda persistiram em muitas organizações, principalmente, nas de caráter industrial, contudo, com a pressão da atual conjuntura de mercado e da sociedade, essas empresas têm voltado seu foco para a prática do conceito de gestão ambiental. Esta mudança de foco dar-se por inúmeros motivos, dentre eles estão à obediência as leis, eficácia nos custos, vantagem competitiva e mudanças na opinião pública. Para tanto, existem inúmeras ferramentas passíveis de aplicação nas organizações para se obter uma gestão ambiental proativa, voltada para a redução dos resíduos e impactos na fonte geradora destes. Em meio a estas, se destacam: a Produção mais Limpa $(\mathrm{P}+\mathrm{L})$, Sistemas de Gestão Ambiental (SGA), Auditoria Ambiental, Ecodesing, Avaliação de Impacto Ambiental, entre outros.

A Produção mais Limpa $(P+L)$ pode ser definida como a aplicação de uma estratégia preventiva e contínua que busca, através de sua integração com os processos existentes nas organizações, atingir a máxima eficiência no uso dos recursos disponibilizados. Esta estratégia, a qual se refere, é de fundamento técnico, econômico e ambiental, cuja finalidade de aplicação é aumentar a eficiência na utilização de matérias-primas, água, e energia por meio da não degradação, redução ou reciclagem dos resíduos e emissões geradas.

A Produção mais Limpa tem relevância devido ao fato de possibilitar, pela sua aplicação, o conhecimento aprofundado das origens dos resíduos poluidores do 
meio ambiente, dando a possibilidade de se reduzir na fonte de geração os rejeitos de produção, além de eliminar desperdícios, minimizar ou eliminar matéria-prima e outros insumos impactantes para o ecossistema. O destaque dado a $\mathrm{P}+\mathrm{L}$, é decorrente de sua abordagem ter como base a proatividade, justamente o oposto da reatividade das ações de fim de tubo e por poder ser aplicada em qualquer setor da economia ou segmento de mercado.

Dentre os setores e segmentos que causam impacto no meio ambiente, destaca-se o segmento de cerâmica vermelha por possuir estrutura e características particulares. Neste setor são produzidos telhas, tijolos e blocos cerâmicos, o que o torna um dos principais fornecedores do setor de construção civil. No Brasil, tal setor apresenta uma grande dificuldade de obtenção de dados estatísticos e indicadores de desempenho, causando, assim, uma deficiência para acompanhar o seu crescimento e melhorar sua competitividade. Além da dificuldade de obtenção de dados, o segmento de cerâmica vermelha apresenta uma série de problemas, tanto ambientais como de qualidade dos produtos.

Os problemas ambientais gerados referem-se, especialmente, a extração e consumo de matérias-primas: argila, água, lenha, etc.; rejeitos de produção, principalmente, produtos defeituosos e emissões gasosas (material particulado), oriundas da queima. Os problemas de qualidade dos produtos são decorrentes do desconhecimento de técnicas modernas de produção de material cerâmico e de normas técnicas sobre a qualidade dos mesmos, dificuldade de obtenção de assistência técnica qualificada, e falta de gerenciamento adequado da produção.

Mediante o contexto, este artigo busca esclarecer o seguinte problema: Como a utilização uma ferramenta de gestão ambiental, a produção mais limpa, pode contribuir para melhorar o processo produtivo das empresas do segmento de cerâmica vermelha?

Com a finalidade de responder ao questionamento levantado, este estudo tem como objetivo: analisar o processo produtivo de uma indústria do segmento de cerâmica vermelha à luz da produção mais limpa, tomando como base teórica o modelo de $\mathrm{P}+\mathrm{L}$ proposto pelo CNTL (2003b).

O presente estudo justifica-se por contribuir com a disseminação da ferramenta $P+L$ e sua aplicação nas empresas, proporcionando benefícios para a 
organização por meio do aperfeiçoamento de suas atividades produtivas, assim como a redução dos impactos causados por tais atividades.

Este artigo estrutura-se da seguinte forma, demais da presente Introdução: referencial teórico apresentando os conceitos referentes à gestão ambiental e $\mathrm{P}+\mathrm{L}$; metodologia, caracterizando o tipo de pesquisa, e coleta de dados; análise dos resultados, destacando a caracterização do segmento de cerâmica vermelha e a avaliação do processo produtivo; e conclusões.

\section{REFERENCIAL TEÓRICO}

\subsection{Gestão ambiental empresarial}

A gestão ambiental empresarial pode ser entendida como a ordenação das atividades organizacionais, com a finalidade de minimizar o impacto ocasionado por estas sobre o meio ambiente, esta ordenação vai desde a escolha das melhores técnicas de gestão até o cumprimento da legislação e a alocação correta de recursos humanos, naturais e financeiros. Para Donaire (2007), gestão ambiental empresarial é um conjunto de políticas, programas e práticas administrativas e operacionais que levam em conta a saúde e segurança das pessoas; a proteção do meio ambiente pela eliminação/minimização de impactos e danos ambientais; e, implantação, operação, ampliação, realocação e desativação de atividades, em todas as fases do ciclo de vida de um produto.

Segundo Drunn, Garcia e Unic (2011), a gestão ambiental é um dos pilares de sustentação do desenvolvimento sustentável, que auxilia as empresas em seus planejamentos ecológicos desenvolvendo uma série desencadeada de benefícios positivos à imagem e os custos organizacionais.

Neste sentido, a gestão ambiental torna-se uma perspectiva importante dentro das organizações que estão interagindo com o ambiente de forma direta, em um ciclo de influência mútuo.

Tendo em vista o conceito de gestão ambiental empresarial, entende-se que as organizações devem buscar incorporá-lo em seu planejamento, adotando, desta forma, uma postura mais proativa. Para tanto, a gestão ambiental empresarial conta 
com uma série de ferramentas passíveis de aplicação que objetivam atender a esse preceito. Dentre as ferramentas de aplicação da gestão ambiental empresarial estão as seguintes: os Sistemas de Gestão Ambiental (SGA); Auditoria ambiental (AA); Ecodesing; Avaliação de Impacto Ambiental (AIA); e, Produção mais Limpa $(\mathrm{P}+\mathrm{L})$. presente estudo centra-se na ferramenta Produção mais Limpa $(P+L)$, apresentada a seguir.

\subsection{Produção mais Limpa $(P+L)$}

A Produção mais Limpa (P+L) consiste, conforme Sperandio e Gaspar (2009), em uma das facetas da operacionalização da gestão ambiental, visto que a adoção de tal ferramenta pelas empresas contribui significativamente para o alcance do desenvolvimento sustentável na parcela que compete às iniciativas organizacionais.

Assim, as primeiras considerações acerca da $\mathrm{P}+\mathrm{L}$ surgiram em meados da década de 80, quando o United Nations Environment Programme (UNEP) estudou setores industriais e concluiu que o custo com tratamento de resíduos gerados em processos de produção era maior do que o custo para eliminá-los ou reduzi-los em suas fontes geradoras. Segundo Berkel (2010), a UNEP, em cooperação com a United Nations Industrial Development Organization (UNIDO), lançou em 1994 um programa para estabelecer e apoiar uma rede global de Centros Nacionais de Produção mais Limpa. Para tanto, os primeiros centros foram estabelecidos ente os anos de 1994 a 1995 na República Checa, Bolívia, Brasil, China, Índia, México, Tanzânia e Zimbabué. Vale salientar que, no Brasil, o centro foi sediado no Serviço Nacional de Aprendizagem Industrial (SENAI) do Rio Grande do Sul, sendo chamado de Centro Nacional de Tecnologias Limpas (CNTL).

A Produção mais Limpa é uma estratégia de aplicação contínua utilizada para evitar as emissões na fonte geradora dos resíduos, e iniciar uma perspectiva de melhoria contínua da prevenção e do desempenho ambiental nas organizações. É uma estratégia preventiva para minimizar os impactos gerados da produção e dos produtos no meio ambiente (FRESNER,1998). Ainda cabe destacar que ela é um conjunto de estratégias técnicas, econômicas e ambientais que são integradas aos processos, com a finalidade de aumentar a eficiência no uso de matérias-primas, 
água e energia, através da não geração, minimização ou reciclagem dos resíduos e emissões geradas com benefícios ambientais, econômicos e de saúde ocupacional (CNTL, 2003a).

Ressalta-se que, dependendo do ponto de vista teórico ou prático, a Produção mais Limpa $(\mathrm{P}+\mathrm{L})$ pode ser entendida como uma ferramenta, abordagem, estratégia ou programa. Para fins deste estudo, a P+L é vista como uma ferramenta da gestão ambiental de caráter estratégico. Visto que, uma vez aplicada poderá proporcionar oportunidades de melhoria no processo produtivo, minimização dos impactos por este gerado no meio ambiente, melhoraria na saúde e segurança no trabalho, além de proporcionar a organização uma série de benefícios de caráter estratégico, como redução nos custos, melhor imagem no mercado e aproveitar oportunidades neste.

O foco da $\mathrm{P}+\mathrm{L}$, como ferramenta estratégica da gestão ambiental, busca atingir a eco-eficiência, reduzir os impactos ambientais e promover a saúde e segurança no ambiente de trabalho. A eco-eficiência é atingida a partir do momento que se é otimizado, através dos princípios da $\mathrm{P}+\mathrm{L}$ o uso de matéria-prima, água e energia, no processo produtivo e se diminui o nível de rejeitos de produção. A redução dos impactos ambientais é obtida quando se introduz uma postura de combate aos agentes causadores destes. Em relação à saúde e segurança no trabalho, essa ferramenta proporciona por intermédio da análise do sistema produtivo a prevenção de acidentes e incidentes de trabalho.

Destaca-se, ainda, que, produção mais limpa é uma ferramenta baseada na proatividade das empresas, que até então tinham seus esforços voltados apenas para o tratamento dos rejeitos e poluentes nos locais de liberação destes por meio de tecnologias de "fim-de-tubo", que se limita a resolver os prejuízos ambientais pelo controle da poluição no fim do processo produtivo. Silva e Medeiros (2004) afirmam que enquanto as técnicas de "fim-de-tubo" são alternativas para remediar ações de agressão ao meio ambiente e esperam que resíduos sejam gerados para, então, tratá-los, a produção mais limpa visa evitar ou diminuir a criação dos resíduos durante o processo produtivo.

Quando uma organização adota os princípios da $\mathrm{P}+\mathrm{L}$, ela está tentando buscar tecnologias que substituam os tratamentos convencionais de "fim- de -tubo" 
por modificações no processo produtivo focadas na prevenção e controle de poluição na fonte (SILVA e MEDEIROS, 2004).

Portanto, a diferença fundamental entre a P+L e técnicas de "fim-de-tubo" está no fato da primeira não tratar apenas das consequências ambientais oriundas da produção e sim buscar atingir a raiz do problema gerador. Entretanto, pode-se considerar que as tecnologias de "fim-de-tubo" constituem uma abordagem antiga e tradicional dos problemas ambientais, enquanto na $\mathrm{P}+\mathrm{L}$ estes são abordados de forma lógica e atual, além do fato desta apresentar com relação às tecnologias de "fim-de-tubo" um conjunto superior de benefícios. Villela Júnior e Demajorovic (2006) destacam entre estes: economia de recursos; melhoria do despenho da empresa com relação às questões ambientais; aumento da eficiência e competitividade; promoção da imagem da empresa; redução de acidentes ambientais; melhoria da conservação dos recursos naturais.

Contudo, mesmo diante dos benefícios proporcionados pela adoção de $\mathrm{P}+\mathrm{L}$, nem todas as empresas conseguem fazer uso de tal ferramenta, pois a situação é decorrente da não superação de algumas barreiras como as conceituais, organizacionais, técnicas, econômicas, financeiras e políticas, apontadas pelo CNTL (2005a).

É importante destacar que, uma vez conhecidas as barreiras a serem enfrentadas, as empresas poderão ter uma melhor performance nas ações de produção mais limpa, e ainda podem buscar subsídios adequados para auxiliá-las nesta prerrogativa, em vários órgãos habilitados para este fim, como: o Centro Nacional de Tecnologias Limpas (CNTL/SENAI), a United Nations Environment Programe (UNEP), a Rede Brasileira de Produção mais Limpa (RBPML), e o Centro de Produção Industrial Sustentável (CEPIS). Tais órgãos contribuem para a disseminação dos princípios de $P+L$ nas empresas, além de fornecerem informações e metodologias de aplicação desta ferramenta.

Com base no que foi apresentado sobre a $\mathrm{P}+\mathrm{L}$, verifica-se que esta é uma ferramenta que tem se consolidado ao longo do seu desenvolvimento, principalmente, por ser uma ferramenta flexível que pode ser adaptada à realidade de cada organização. Logo, a Produção mais Limpa tem sido adotada em diversos 
países nos mais diferentes tipos de empresas, que por sua vez se tornaram alvo de vários estudos empíricos, como mostra o quadro 1.

Quadro1 - Avaliação dos procedimentos da empresa
\begin{tabular}{|c|c|c|}
\hline $\begin{array}{c}\text { AUTOR / ANO DE } \\
\text { PUBLICAÇÃO }\end{array}$ & PAís & TIPO DE EMPRESA OU SETOR DE ATUAÇÃo \\
\hline GAIKA (2004) & Polônia & Agricultura e criação de gado \\
\hline BERKEL (2007) & Austrália & $\begin{array}{c}\text { Refinamento de petróleo, processamento mineral, e produção } \\
\text { de Metal }\end{array}$ \\
\hline $\begin{array}{c}\text { OLIVEIRA E } \\
\text { ALVES (2007) }\end{array}$ & Brasil & Usinagem \\
\hline $\begin{array}{c}\text { GIANNETTI et al } \\
(2008)\end{array}$ & Brasil \\
\hline $\begin{array}{c}\text { TANAPONGPIPAT } \\
\text { t al (2008) }\end{array}$ & Tailândia & Fabricação de joias banhada a ouro \\
\hline $\begin{array}{c}\text { KIST, MOUTAGI e } \\
\text { MACHADO (2009) }\end{array}$ & Brasil & Matadouro de Aves \\
\hline $\begin{array}{c}\text { SEVERO e OLEA } \\
(2010)\end{array}$ & Brasil & Automotiva (metal mecânico) \\
\hline $\begin{array}{c}\text { VENDRAMETTO } \\
\text { et al (2010) }\end{array}$ & Brasil & $\begin{array}{c}\text { Indústria automobilística e de suprimentos médicos (produtora } \\
\text { de equipamentos para uso em hemodiálise) }\end{array}$ \\
\hline $\begin{array}{c}\text { HUANG, LUO e } \\
\text { XIA (2013) }\end{array}$ & China & Produção de telha cerâmica \\
\hline
\end{tabular}

Fonte: Elaboração a partir da revisão da literatura (2013)

O quadro 1 evidencia estudos realizados em várias empresas no que tange à aplicação dos preceitos da Produção mais Limpa $(\mathrm{P}+\mathrm{L})$. Diante do exposto, verificase que tal ferramenta tem sido aplicada frequentemente no Brasil, neste sentido a seguir são apresentados com base na literatura nacional três metodologias para implementação da Produção mais Limpa.

\subsection{Metodologias para a implementação da Produção mais Limpa.}

Com base na revisão da literatura nacional foram identificadas três metodologias de implementação da Produção mais Limpa propostas por Vilela Júnior e Demajorovic (2006); Rede Brasileira de Produção mais Limpa; e, CNTL (2003b). O presente estudo optou pela metodologia apresentada pelo CTLN (2003b), isso devido a sua amplitude e detalhamento.

A abordagem criada pelo CNTL (2003b) divide o processo de $\mathrm{P}+\mathrm{L}$ nas organizações em cinco fases distintas: Planejamento e Organização; Pré-avaliação; Avaliação; Estudo da viabilidade; e, Implementação. A metodologia do CNTL 
(2003b) apresentar-se como a mais completa entre as metodologias descritas e pode ser utilizada em setores da economia, haja vista o foco de estudo. Porém, dada à amplitude desta metodologia e às limitações de tempo e recursos na realização do presente estudo, optou-se pela aplicação dos passos 5, 6, 7,9 e 10 das fases de avaliação e pré-avaliação, destacadas na figura 1.

Figura 1 - Metodologia de $\mathrm{P}+\mathrm{L}$ proposta pelo CNTL

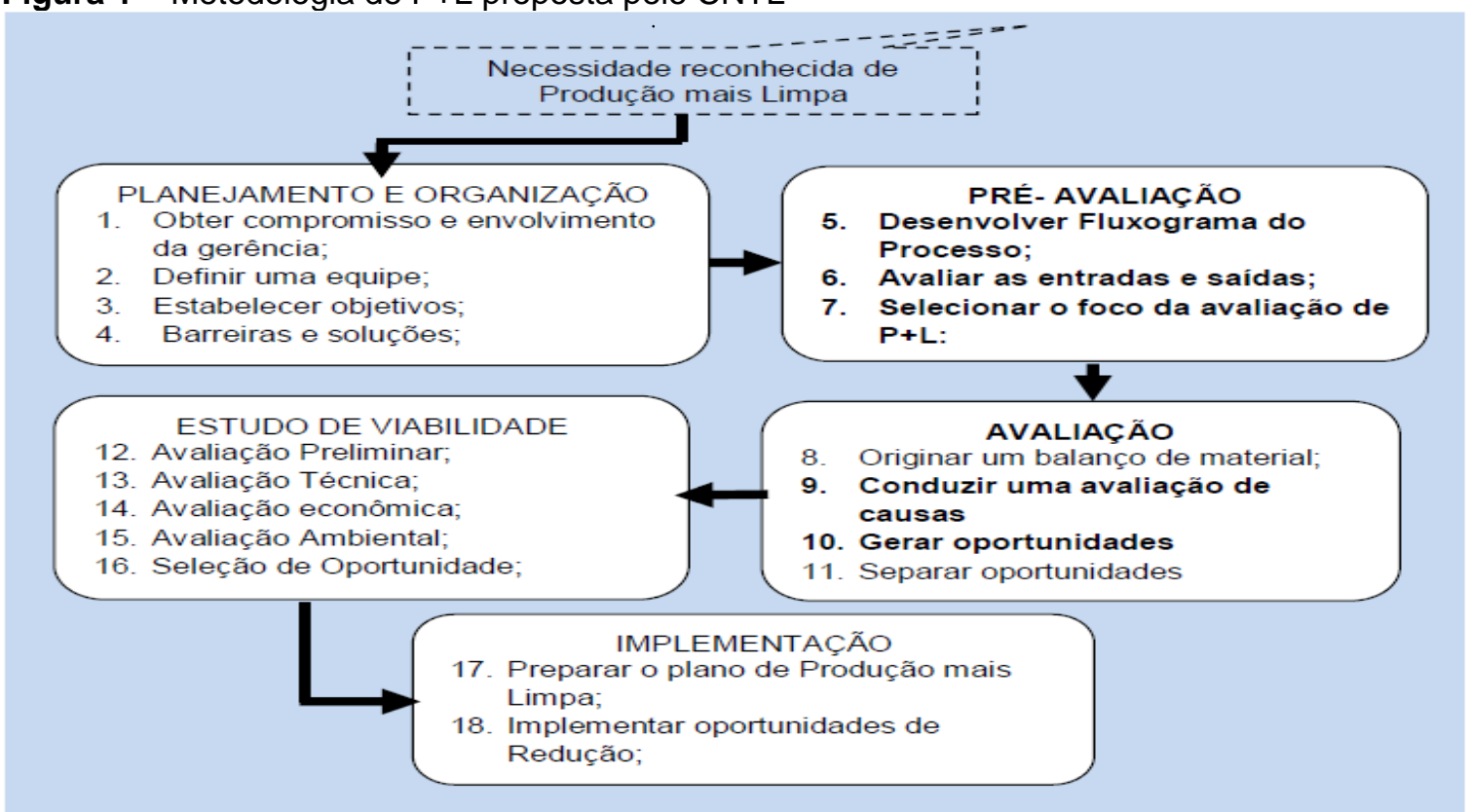

Fonte: Adaptado do CNTL (2003b)

Uma vez apresentados os fundamentos teóricos que nortearão o estudo, em seguida são apresentados os aspectos metodológicos utilizados na pesquisa.

\section{METODOLOGIA}

Diante do objetivo proposto, tomando como base teórica o modelo de $\mathrm{P}+\mathrm{L}$ proposto pelo CNTL (2003b), o presente trabalho caracterizou-se como exploratório e descritivo. Exploratório devido ao fato de visar conhecer os fatos e fenômenos relacionados ao tema de estudo, e por explorar um tema ainda em construção e com um número relativamente baixo de trabalhos realizados na área. Descritiva, por fazer um levantamento das características conhecidas, componentes do fato/fenômeno/processo e ter como objetivo, conforme o apresentado por Marconi e Lakatos (1999), descrever, registrar, analisar e interpretar os fenômenos atuais. 
Para a devida operacionalização da pesquisa, utilizou-se o estudo de caso, devido este, segundo Yin (2005), ser uma forma de se fazer pesquisa investigativa de fenômenos atuais dentro de seu contexto real, nas situações em que as fronteiras entre o fenômeno e o contexto não estão claramente estabelecidos. Contudo, os estudos de casos podem envolver como recursos para a coleta de dados a análise de arquivos, a realização de entrevistas, a aplicação de questionários e a observação.

Vale salientar que, o questionário foi aplicado ao proprietário e a entrevista feita também com o proprietário e o gerente de produção, sendo a observação não participante a cargo da pesquisadora. O questionário aplicado foi adaptado do Centro Nacional de Tecnologias Limpas- CNTL (2003b), destacando-se o fato que o presente trabalho se limitou as etapas de pré-avaliação e avaliação dentre as cinco fases propostas por esta. O objetivo do questionário foi identificar, através do ponto de vista do proprietário, se a empresa está promovendo ou poderia promover Produção mais Limpa. Sendo composto por trinta e uma questões, em que oito abordou aspectos gerais; quinze do plano de operações; três do plano financeiro; três do arquivo de dados; e duas do plano de marketing. Como opções de resposta foram dadas SIM, NÃO e NÃO TEM CERTEZA, em que, o sim indica que a empresa está promovendo ou poderia promover a produção mais limpa, o não significa que a empresa não adota práticas de produção mais limpa e o não tem certeza significa que precisa avaliar melhor a respectiva atividade.

A coletada de dados teve início em 01/03/10 e fim em 03/04/10. Quanto à entrevista, optou-se por aplicar essa técnica junto ao proprietário e o gerente de produção. Nela, buscou-se, por meio de um roteiro semi-estruturado, identificar em quais áreas da empresa poderiam estar às oportunidades de aplicação da $P+L$ e quais seriam estas oportunidades. A escolha da entrevista junto ao gerente de produção foi feita devido esta ser adequada para se obter amplamente a descrição do processo produtivo da empresa, sendo que ambos possuem forte experiência no segmento atuando há treze anos nele.

A observação não participante foi escolhida como técnica pela pesquisadora devido ao fato desta possibilitar a identificação de fatores importantes para o estudo, tais como: ambiente de chão de fábrica, resíduos dispostos no pátio, desperdícios 
durante e produção, manuseio de matéria- prima e produtos acabados, foram feitas quatro visitas a fabrica com a duração média de cinco horas.

Para a coleta de dados de fonte secundária, optou-se por um levantamento através de pesquisa relatórios, artigos, e estudos realizados no segmento de cerâmica vermelha a fim de conhecer e descrever o segmento o qual o objeto de estudo se encontra inserido, além de documentos, relatórios existentes na empresa, planilhas de controle de produção, etc. com o intuito de analisar e descrever melhor o processo produtivo e identificar as oportunidades de $\mathrm{P}+\mathrm{L}$.

Dados quantitativos foram considerados em termos de grandezas ou quantidade o fator presente em uma dada situação, sendo estes expressos em números enquanto que, os dados qualitativos foram baseados na presença ou ausência de uma qualidade ou característica, e também na classificação de tipos diferentes de dada propriedade (MARCONI e LAKATOS,1999).

O procedimento qualitativo foi adotado para o entendimento e caracterização de todo o estudo de caso e o procedimento quantitativo foi utilizado para mensurar dados de volume de produção, consumo de energia e água, rejeitos de produção, entre outros. Uma vez explicitados os aspectos metodológicos que deram suporte a pesquisa a seguir serão apresentados e analisados os dados obtidos.

\section{ANÁLISE DOS RESULTADOS}

O setor de cerâmica, em função de diversos critérios como matérias-primas empregadas, propriedades e utilização dos produtos fabricados, é composto pelos seguintes segmentos: cerâmica branca; cerâmica de revestimentos; materiais refratários; isolantes térmicos; cerâmica de alta tecnologia e cerâmica vermelha.

No Brasil, o segmento de cerâmica vermelha é composto, em grande parte, por empresas familiares, de micro, pequeno e médio porte e com processos produtivos e tecnologia, em muitos casos, defasados. Localizadas nas diversas regiões do país, elas firmam suas instalações em regiões com disponibilidade de matéria-prima e utilizam-se do modal rodoviário para o transporte de seus produtos, além de terem como maiores custos o de combustível para etapa de queima e a mão-de-obra, sendo esta última, em sua maioria, de pouca qualificação e de alto 
grau de rotatividade. No que tange o número de empresas no segmento no país, segundo a Associação Brasileira de Cerâmica-ABC, tomando como base uma pesquisa realizada em 2003, é de 7.000.

É importante destacar que, há uma carência de informações sobre o segmento de cerâmica vermelha, principalmente, que espelhem a efetiva caracterização e composição deste. Dentre as informações obtidas, pode-se destacar algumas dificuldades que o segmento enfrenta, tais como: processos produtivos ultrapassados; defasagem tecnológica e obsolescência de maquinário; falta de conhecimento técnico para preparação da argila; ausência de critérios para dosagem de resíduos; falha no processo de extrusão; falta de regulagem das boquilhas, entre outros. Para tanto, se faz necessário uma visão do processo produtivo da cerâmica vermelha, a fim de identificar estas dificuldades, localizar desperdícios de resíduos do processo, assim, podendo a frente diagnosticar os impactos ambientais, econômicos e sociais associados a este.

No Brasil, existem poucos estudos que avaliam impactos ambientais relacionados à produção ao segmento de cerâmica vermelha focados na fabricação de telhas, tijolos, blocos e similares. Sendo assim, aumenta a dificuldade de se definir requisitos voltados ao desempenho ambiental das empresas produtoras.

Os poucos estudos no segmento mostram que os impactos ambientais nele estão geralmente associados a determinados fatores, como: consumo e tipo energético utilizado pelas indústrias; consumo de água no processo produtivo; perdas no processo produtivo; emissão de poluentes grassos, líquidos e sólidos; ocupação e degradação do solo; transportes de materiais de consumo e produtos cerâmicos; jazidas (vida útil, localização, valor ecológico das áreas e restauração das áreas degradas; e geração de resíduos (GRIGOLETTI e STTLER, 2003). Neste sentido, diante do cenário em que se caracteriza o setor de cerâmica evidencia-se a seguir a empresa foco do presente estudo.

\subsection{A Empresa}

A empresa foco deste estudo é a Cerâmica Alfa, assim denominada para se preservar sua identidade, foi fundada na zona rural do município de Santa Luzia-PB, 
em agosto de 1997. Iniciou suas atividades produzindo em pequena escala telhas, tijolos e blocos cerâmicos de forma simples (em torno de 300mil peças por mês), a fim de suprir a demanda da Madeireira Alfa- LTDA por tais produtos, salientado o fato de ambas as empresas serem do mesmo proprietário. Devido à necessidade do empreendimento reduzir seus custos de produção e encontrar um ponto de equilíbrio financeiro por causa do aumento destes, a empresa expandiu sua capacidade produtiva até a região e cidades circunvizinhas de Santa Luzia- PB, além de permanecer como seu principal cliente a Madeireira Alfa - LTDA.

Entre algumas características particulares da empresa, destacam-se: a melhor época de vendas ocorre no período de janeiro a março devido ao possível aumento das chuvas; seus maiores custos estão no consumo de lenha, energia elétrica e argila, como também a mão-de-obra; e seus principais concorrentes são três olarias da região circunvizinha, entre estas a que possui maior potencial, a olaria Santo Antônio, que produz apenas telhas.

Classificada pelo SEBRAE como pequena empresa pelo fato de sua receita anual está estimada em $\mathrm{R} \$$ 1.872.000,00, a Cerâmica Alfa possui um volume de produção em torno de $7.275 \mathrm{mil} /$ telhas ano, $6.789 \mathrm{mil} /$ tijolos ano e $174 \mathrm{mil} / \mathrm{blocos}$ ano. A empresa comporta em sua estrutura atual 61 funcionários, sendo estes um gerente geral de produção, um auxiliar de escritório, um controlador de expedição e 58 no setor produtivo, ressaltando que as questões de cunho estratégico ficam a cargo dos proprietários.

\subsection{Diagnóstico da empresa em estudo: avaliação generalista dos procedimentos da Cerâmica Alfa referente à Produção mais Limpa}

Com base na etapa de pré-avaliação, proposta pela metodologia escolhida procurou-se diagnosticar, de maneira geral, através da aplicação de um questionário com o proprietário da Cerâmica Alfa, se a indústria vem praticando ações de produção mais limpa e se esta estaria apta comportar a aplicação desta ferramenta. Este diagnóstico tem como a finalidade facilitar a compreensão do atual universo do objeto de estudo. O questionário aplicado ao proprietário é composto cinco blocos 
de questões, os quais as principais respostas são apresentadas no quadro 2, a seguir.

Quadro 2 - Avaliação dos procedimentos da empresa

\begin{tabular}{|c|c|c|c|}
\hline Bloco & Resposta Positiva & Resposta negativa & Não tem certeza \\
\hline $\begin{array}{c}\text { Aspectos } \\
\text { Gerais }\end{array}$ & $\begin{array}{l}\text { O Proprietário tem conhecimento } \\
\text { sobre os conceitos relacionados à } \\
\mathrm{P}+\mathrm{L} \text {; empresa está sujeita a } \\
\text { A em } \\
\text { regulamentos ambientais; } \\
\text { O proprietário conhece os } \\
\text { regulamentos ambientais que } \\
\text { influenciam sua empresa; } \\
\text { Tem investido em medidas de } \\
\text { proteção ambiental; } \\
\text { Tem boa reputação perante a } \\
\text { comunidade; }\end{array}$ & $\begin{array}{l}\text { Existência de um } \\
\text { responsável ou setor } \\
\text { focado nas questões } \\
\text { ambientais; } \\
\text { Existência de um } \\
\text { plano comercial de } \\
\text { longo prazo. }\end{array}$ & $\begin{array}{l}\text { Alta prioridade do } \\
\text { meio ambiente para } \\
\text { empresa. }\end{array}$ \\
\hline $\begin{array}{c}\text { Plano } \\
\text { de } \\
\text { Operaçōes }\end{array}$ & $\begin{array}{l}\text { Conhecimento dos funcionários e } \\
\text { Gerência sobre } P+L ; \text { Conhecimento } \\
\text { da quantidade de resíduos e } \\
\text { emissões do processo produtivo; } \\
\text { Controle de estoque; } \\
\text { Antes de investir em equipamentos } \\
\text { solicita informações sobre o tipo e } \\
\text { quantidade de resíduos e emissões } \\
\text { por ele gerados; } \\
\text { Já buscou utilizar resíduos de outro } \\
\text { processo produtivo, etc. }\end{array}$ & $\begin{array}{l}\text { Desenvolve } \\
\text { atualmente nenhum } \\
\text { programa de } \mathrm{P}+\mathrm{L} \text {; } \\
\text { Reciclagem de todos } \\
\text { resíduos possíveis; e } \\
\text { Avaliações } \\
\text { periódicas de } \mathrm{P}+\mathrm{L} \text {. }\end{array}$ & $\begin{array}{l}\text { Se todos seus } \\
\text { funcionários são } \\
\text { treinados sobre } \\
\text { como agir em caso } \\
\text { de incidentes de } \\
\text { trabalho. }\end{array}$ \\
\hline $\begin{array}{c}\text { Plano } \\
\text { Financeiro }\end{array}$ & $\begin{array}{l}\text { Considera o custo na disposição de } \\
\text { resíduos quando realiza declaração } \\
\text { de lucros e perdas; } \\
\text { Conhece os custos da produção de } \\
\text { resíduos e emissões associados ao } \\
\text { processo produtivo; e } \\
\text { Inclui esses custos no preço do } \\
\text { Produto. }\end{array}$ & & \\
\hline $\begin{array}{l}\text { Arquivo de } \\
\text { dados }\end{array}$ & $\begin{array}{l}\text { Arquiva dados sobre quantidade de } \\
\text { matéria-prima utilizada no processo; } \\
\text { e adotada controles sobre os tipos e } \\
\text { quantidades de resíduos e emissões } \\
\text { geradas pela empresa. }\end{array}$ & $\begin{array}{lr}\text { Existência } & \text { de } \\
\text { Políticas Escritas } \\
\text { para documentar os } \\
\text { procedimentos } \\
\text { padrões de } \\
\text { Operações. }\end{array}$ & \\
\hline $\begin{array}{l}\text { Plano de } \\
\text { Marketing }\end{array}$ & $\begin{array}{l}\text { Incorporação da imagem positiva } \\
\text { relacionada à } \mathrm{P}+\mathrm{L} \text {; e divulgação dos } \\
\text { esforços para redução de resíduos e } \\
\text { emissões. }\end{array}$ & & \\
\hline
\end{tabular}

Fonte: Elaboração a partir de dados da pesquisa, 2010

Com base nas informações expostas no quadro 2, estas indicam que a empresa tem conhecimento do que vem a ser uma Produção mais Limpa, fato que facilitaria a aplicação da ferramenta. Entretanto, a aplicação teria dificuldades na 
operacionalização das etapas de implantação por não ter um setor ou alguém responsável pelos assuntos ambientais e assim como um plano estratégico a longo prazo, já que para se obter sucesso na aplicação desta ferramenta faz-se necessário que ela faça parte do plano estratégico da empresa. No que tange ao plano de operações, observa-se que a empresa estudada conhece os resíduos gerados por suas atividades produtivas e busca, mesmo de uma forma superficial, controlá-los. Entretanto, ela precisa criar mecanismos de avaliação e programas de desenvolvimento de funcionários ligados a produção mais limpa para melhorar seu desempenho nestas questões.

Referente ao plano financeiro, a empresa possui interesse de reduzir seus custos e prejuízos oriundos do desperdício dos recursos e de resíduos, visando à saúde financeira da empresa. No bloco de arquivo de dados, as respostas mostram que a empresa possui um arquivo de dados relativamente bom, visto que este poderia ser melhorado se existisse uma política que esclarecesse quais os procedimentos padrões a serem desempenhados na produção dela, o que possibilitaria comparar padrões com o realmente desempenhado.

E por último, as respostas obtidas sobre plano de marketing demonstram que, embora a empresa apresente práticas que levem a $\mathrm{P}+\mathrm{L}$, esta não faz nenhuma divulgação a respeito destas para seu público externo. Analisando o questionário aplicado ao proprietário, pode-se notar que a empresa, na maioria dos aspectos levantados, possui resposta positiva o que indica que esta já pratica algumas ações relacionadas à produção mais limpa, entretanto, esta pode apresentar oportunidades de $P+L$ ainda não identificadas pela mesma. Desta forma, se faz necessária a descrição do seu processo e uma análise mais detalhada apresentada adiante.

\subsection{Análise do processo produtivo da empresa Alfa, identificação de resíduos e seus respectivos impactos}

Com base nas etapas de pré-avaliação e avaliação da metodologia escolhida, para se identificar os resíduos, efluentes e emissões oriundas do processo produtivo faz-se necessário o desenho de um fluxograma simples do processo de produção, pelo qual será possível identificar as etapas do processo produtivo e suas entradas e 
as saídas. O fluxograma do processo produtivo da empresa Alfa será representado na figura 2.

Figura 2 - Fluxograma do processo produtivo.

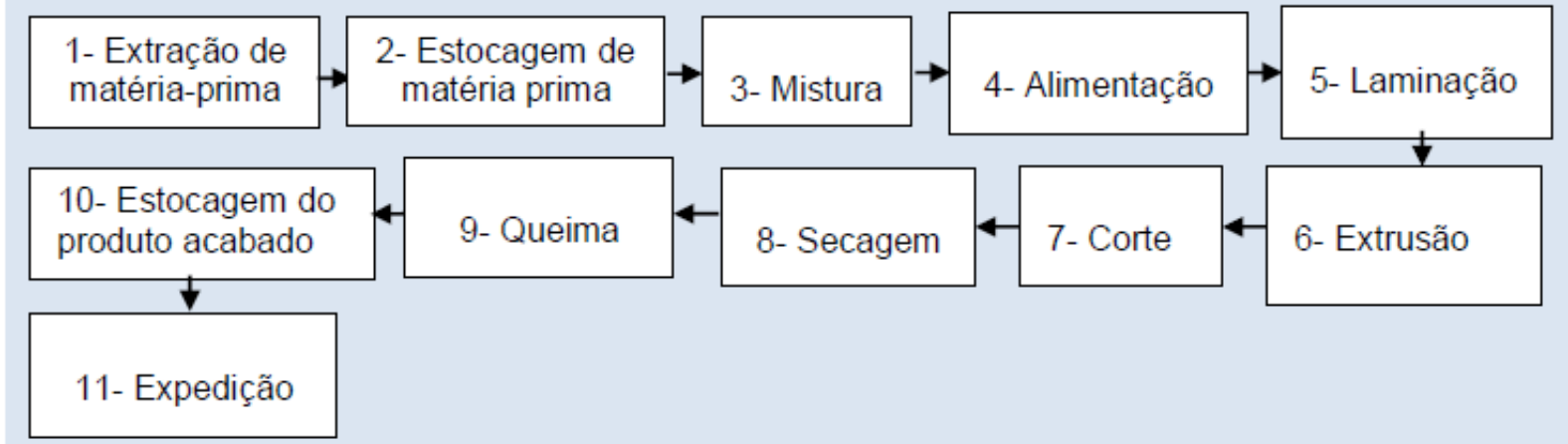

Fonte: Elaboração a partir de dados da pesquisa, 2010.

Com base na figura 2, é possível descrever cada etapa do processo produtivo e identificar os resíduos gerados pela empresa em estudo. Uma vez identificados estes resíduos, é fundamental, segundo a metodologia de $\mathrm{P}+\mathrm{L}$ escolhida, diagnosticar as possíveis causas de sua geração, assim como os impactos gerados pela etapa como todo. Com a finalidade de melhor compreensão, será apresentada a seguir esta análise.

a) Extração de matéria-prima: A principal matéria-prima da produção de cerâmica vermelha é a argila. A empresa estudada está localizada próxima à área de abundância desta matéria-prima, sendo assim, toda argila que abastece o processo é adquirida por meio de extração dos rios, barreiros, etc. existentes na região e não em jazidas. A extração é feita a céu aberto através de um trator com uma pá carregadeira e o transporte do local de extração até a fábrica é realizado por caminhões caçamba abertos, sem uso de lona para proteção do material, percorrendo uma distância de aproximadamente $60 \mathrm{~km}$. A extração é feita nos períodos de seca, entre os meses de novembro a maio.

Impactos e iniciativas da empresa: Os principais impactos de caráter ambiental diagnosticado nesta etapa foram: a degradação do solo, o consumo de recurso natural e a poluição do ar por meio da suspensão de material particulado, oriundo da extração e emissão de $\mathrm{CO}_{2}$. Quanto à degradação do solo, a empresa para reduzir este impacto faz-se a extração desta matéria-prima através da limpeza de açudes particulares no período de seca, na opinião do empresário esta prática 
permite aumentar a capacidade de acúmulo de água do açude nos períodos chuvosos, recompensando o impacto causado pela retirada da argila do mesmo. Quanto à poluição do ar pela emissão de $\mathrm{CO}_{2}$ oriunda do transporte da argila até a empresa, verifica-se uma diminuição desta emissão, visto que a indústria é localizada em um local de abundância de argila a um raio de $60 \mathrm{~km}$, no entanto, a emissão deste gás pela atividade do trator, assim como a suspensão de material particulado durante a extração e transporte (que é feito em carro aberto sem cobertura), não se verificou medidas de redução praticadas.

Pode-se identificar como impacto a saúde do trabalhador, nesta etapa, a exposição a vibrações e ruídos oriundos da atividade do trator, e inalação do material particulado suspenso durante a extração e transporte da matéria-prima. A empresa busca reduzir estes impactos através do fornecimento de equipamentos de proteção individual. Neste caso, com o uso do protetor auricular e de máscaras com filtro respirador. No que tange os impactos econômicos, pode-se considerar que há compra de argila de má qualidade, devido à falta de análise do solo antes do ato da compra, o que ocasiona perda de capital e extração desnecessária do recurso do meio ambiente; e desperdício de óleo diesel pelo fato do trator utilizado ser antigo consumindo mais este insumo do que um equipamento mais moderno. A empresa não adota nenhuma medida específica para reduzir os impactos econômicos identificados nesta etapa.

b) Estocagem de matéria-prima: A argila após a extração permanece estocada no pátio da empresa a céu aberto para a maturação, por um período de seis meses, esta pratica é chamada de sazonamento. Durante esse tempo, ocorre à decomposição da matéria orgânica presente na camada de solo, tornando a matéria prima mais pura e homogênea para a sua entrada no processo produtivo. Para o sazonamento, no pátio a argila é separada em montes de acordo com a qualidade, onde a mais fraca, com maior quantidade de areia (argila clara), e a mais forte com, menor quantidade de areia (argila escura), ficam separadas em locais específicos.

Impactos e iniciativas da empresa: O impacto de caráter ambiental diagnosticado, nesta etapa, foi a poluição do ar por suspensão de material particulado e emissão de $\mathrm{CO}_{2}$ oriunda da atividade do trator. Assim como, na etapa 
anterior, a empresa não possui práticas para reduzir este impacto. Quanto aos impactos causados à saúde do trabalhador, identificaram-se os mesmos impactos citados na etapa acima, o qual as medidas adotadas pela empresa são as mesmas. Quanto aos impactos econômicos não se identificou perda de matéria-prima nesta fase, apenas foi diagnosticado, como a etapa anterior, que o desperdício de óleo diesel devido ao trator utilizado ser antigo.

c) Mistura: corresponde à preparação da argila antes que a mesma seja encaminhada ao caixão alimentador. Nesta etapa, são misturados os dois tipos de argila, a fraca e forte na proporção 2:1. A finalidade desta etapa é corrigir a plasticidade a argila mantendo a mistura homogênea, de modo a conseguir a uniformidade física e química da massa. Para tanto, se adiciona a água para umedecer a argila e facilitar a homogeneização, e com a ajuda de um operador e um trator com pá carregadeira a argila, enfim, é homogeneizada, enquanto a pá carregadeira homogeneíza a argila, outro (os) colaborador (es) quebra (m) os torrões, retira $(m)$ as pedras e raízes visíveis enquanto estas existirem. Cabe destacar que essa mistura fica a disposição da etapa de alimentação por dois dias.

Impactos e iniciativas da empresa: os impactos identificados na etapa de mistura são os mesmos identificados na atividade anterior, bem como suas respectivas medidas mitigadoras.

d) Alimentação: Esta etapa consiste no transporte da mistura por um trator com a pá carregadeira até o caixão alimentador, o qual se destina a alimentação constante da argila através de uma esteira no processo de fabricação. O caixão alimentador é uma estrutura de elevada resistência que permite a colocação de um volume considerável de argila sobreposto, este fato amplia a capacidade de armazenagem evitando perdas de argila.

Impactos e iniciativas da empresa: os mesmos impactos e iniciativas identificados nas etapas anteriores.

e) Laminação: O laminador fica logo em baixo do caixão alimentador e seguinte a um equipamento que retira pedras existentes na massa. Ele é destinado ao 
processo cerâmico contemplando a homogeneização da argila. O laminador fraciona os pedriscos, laminando-os e misturando-os a massa cerâmica. Esta etapa evita perdas na produção e proporciona produtos com melhor acabamento. É importante destacar que a qualidade da laminação pode determinar o acabamento dos produtos e uma redução no consumo de energia para queima visto que a granulometria diminui.

Impactos e iniciativas da empresa: $\mathrm{Na}$ etapa de laminação, não foram diagnosticados resíduos e impactos.

f) Extrusão: Nesta etapa, a massa é colocada na extrusora, também conhecida como maromba, onde é compactada e forçada por um eixo helicoidal através de um bocal (boquilhas), apropriado ao tipo de peça a ser produzida. As extrusoras utilizadas pela empresa, nesta etapa, são recomendadas para a fabricação de tijolos aparentes, bem como telhas que necessitam de uma massa mais homogênea e uniforme, as extrusora de tijolos, blocos e telhas utilizadas pela empresa possuem dois caracóis, sendo o primeiro para o recebimento da argila e o segundo na extrusão. Como resultado desta etapa, obtém-se uma coluna com seção transversal e formato e dimensões desejados.

Impactos e iniciativas da empresa: $\mathrm{Na}$ etapa de extrusão, os impactos são oriundos do resíduo identificado de massa moldada com deformações. Isto ocorre quando algum pedrisco que não retirado etapas anteriores, fica preso na extrusora. Este resíduo não foi possível quantificar, mas sua geração causa, como o impacto ao meio ambiente, o aumento do consumo de energia elétrica, água, e argila, visto que todos estes recursos utilizados na produção foram desperdiçados assim como a mão-de-obra empregada no processo. Com relação ao impacto econômico para empresa, a geração deste resíduo cria custos adicionais devidos os desperdícios. A empresa faz o reaproveitamento deste resíduo através do retrabalho, direcionando este para etapa de mistura onde ele será quebrado e agregado à massa.

g) Corte: Na saída do fluxo da extrusora está à mesa de corte, formada por arames presos a um esquadro de metal. O corte é sincronizado e preciso que se diferencia 
devido seu sistema de corte horizontal, reduzindo as rebarbas e deformações nos elementos de argila. Depois do corte, os produtos são transportados por meio de carrinhos de mão específicos para a área de secagem do produto semiacabado.

Impactos e iniciativas da empresa: os resíduos identificados foram às aparas do corte, telhas, tijolos e blocos defeituosos e arame desgastado no processo. Segundo dados estimados pelo Centro de Produção Industrial Sustentável-CEPIS (2008), em consultoria prestada na empresa, os tijolos e telhas defeituosos oriundos do corte somam em torno de 11.339 unidades/mês. É importante destacar que, os tijolos e telhas defeituosos no corte geram como impacto o aumento do consumo dos recursos de produção bem como custos adicionais devido à perda de energia elétrica, água e mão-de-obra. No que se refere à quantificação do arame e aparas do processo, esta não foi possível de ser realizada. A empresa para diminuir o impacto causado pelos tijolos, telhas e blocos defeituosos, assim como as aparas de corte, tem feito retrabalho destes resíduos, o que elimina a perda de argila. Com relação ao arame, não foi identificado nenhuma prática da empresa para diminuir ou reciclar este resíduo.

h) Secagem: A secagem nesta indústria é feita por meio natural, em um galpão coberto, onde é armazenado como produto semi-acabado, no verão este fica durante oito dias, podendo chegar até quinze dias no inverno. No que se refere à secagem da telha, esta ocorre no pátio exposta ao sol levando um dia para secagem, salientado que caso ocorra chuva toda produção é perdida.

Impactos e iniciativas da empresa: Como impactos identificados nesta etapa estão o desperdício dos insumos de produção aplicados ao longo de todo processo, visto que quando a produção das telhas é perdida tudo que foi utilizado, até então, também é perdido, o que gera custos adicionais. Quanto à saúde do trabalhador a exposição deste ao sol é considerada um impacto. Para reduzir os impactos ambientais e econômicos dos resíduos à empresa faz também o retrabalho aproveitado às telhas defeituosas, no referente à exposição do trabalhador ao sol ela fornece equipamentos de proteção e disponibiliza avaliações para constatar de esta exposição fora da normalidade. 
i) Queima: De todas as etapas, esta é a mais importante, pois é nesta etapa que o produto cerâmico sofre alterações e transformações químicas e físicas dentro do forno. A queima das telhas é feita em fornos Caipiras, aquecido a lenha de forma lenta e gradual até atingir o ponto final da queima. Quanto aos tijolos e blocos, estes são queimados em um forno Hoffman o qual possui controle da temperatura, mas também é aquecida a lenha.

Impactos e iniciativas da empresa: Como impactos, destacam-se: o consumo da lenha, poluição do ar por meio das cinzas e $\mathrm{CO}_{2}$ liberado pela queima. A lenha incorporada neste processo é de plantio próprio, e segundo o proprietário por este motivo não se necessita de certificação. Como impacto econômico, desta etapa produtiva, está o desperdício em torno de peças quebradas ou de má qualidade, que ocasionam custos adicionais e a perda do calor forno que poderia ser utilizada para outros fins. O impacto diagnosticado, no que tange a saúde do trabalhador, está à exposição ao calor. Para reduzir os impactos desta fase a empresa está investindo em um forno Sedan para queima das telhas, o qual recicla, em até $80 \%$, o calor gerado, possibilitando a transferência deste para estufas e reduz o lançamento de poluentes, consumo da lenha e produtos defeituosos. E os resíduos já existentes são vendidos em uma pequena porcentagem para pavimentação de ruas. Quanto ao impacto causado à saúde do trabalhador, a empresa busca monitorar o grau de exposição ao calor e disponibiliza equipamentos de proteção.

j) Estocagem do produto acabado e Expedição: As telhas, os blocos e os tijolos, são armazenados a céu aberto em uma plataforma nas laterais do forno sem identificação de quantidade e qualidade. Na expedição, enquanto o caminhão é carregado, o motorista dirige-se ao escritório para solicitar a nota fiscal dos produtos a serem transportados. Após o carregamento, o carro passa pela conferência do responsável pelo setor de expedição e é liberado para seguir viagem até o destino especificado pelo comprador da carga dos produtos. Geralmente, este destino é as cidades vizinhas de Santa Luzia-PB ou a cidade de Queimadas-PB, onde se localizam seus principais clientes. 
Impactos e iniciativas da empresa: Os resíduos identificados, nesta etapa, resumem-se a produtos quebrados. Segundo o proprietário, estima-se $10 \%$ destes resíduos entre as etapas de queima, estocagem e expedição. Para tanto, os impactos ambientais e econômicos são oriundos do desperdício dos recursos de produção nesta porcentagem de perda.

Apresentados a análise do processo produtivo e seus respectivos impactos assim como as iniciativas praticadas pela empresa se faz necessário algumas considerações que serão apresentadas a seguir.

\section{CONSIDERAÇÕES FINAIS}

O presente estudo teve como objetivo analisar o processo produtivo de uma indústria de Cerâmica Vermelha à luz de uma Produção mais Limpa $(\mathrm{P}+\mathrm{L})$.

Para se responder a problemática abordada, buscou-se fazer um diagnóstico na Cerâmica Alfa a fim verificar os procedimentos desta que se referem à produção mais limpa. Através dos dados obtidos pode-se chegar à conclusão que a empresa estudada encontra-se em um estágio inicial de desenvolvimento das práticas que levam a uma Produção mais Limpa. É importante ressaltar que, tal diagnóstico representa apenas o ponto de vista do proprietário, o que torna restrito a este, sendo assim, se a empresa tiver interesse na efetiva aplicação de $P+L$ deve-se ser feito esta análise no ponto de vista dos demais integrantes da organização.

Assim, conclui-se que as etapas que geram o maior volume de resíduos não reciclados ou retrabalhados pela empresa estudada (telhas, blocos e tijolos quebrados ou defeituosos) são as etapas de queima, estocagem de produto acabado e expedição. Outra conclusão importante obtida é que, os principais impactos causados ao meio ambiente pela Cerâmica Alfa são: a poluição do ar por meio de emissão de $\mathrm{CO}_{2}$ em cinco das onze etapas produtivas; poluição do ar pela poeira e cinza (suspensão e emissão de material particulado), degradação do solo na extração, desperdícios no consumo de recursos naturais como energia, água e argila. Os impactos causados à saúde do trabalhador são a exposição ao sol, ao calor do forno, poeira, ruído e vibrações. E econômicos estão relacionados a custos adicionais devidos o desperdício de matéria-prima e retrabalho. 
Tendo em vista os princípios da produção mais limpa e os impactos identificados, sugere-se que a empresa, para reduzir os impactos: incorpore resíduos de outros processos na forma de matéria bruta, reduzindo o consumo de argila; faça análise de solo antes da extração, evitando a extração desnecessária de argila não adequada para a produção; faça parcerias com universidades, a fim de obter acesso a laboratório de análise de solo; uso de filtro antipoluente, melhorando as condições de trabalho para o operador e reduzindo a emissão de $\mathrm{CO}_{2}$; adquira uma grelha filtro com menor abertura, evitando a passagem de pedras que deformem a massa durante a modelagem na extrusora; faça manutenção das boquilhas; utilize um arame de qualidade, para reduzir falhas no corte; realize manutenção preventiva das maquinas, rolamento, rolo e esteira transportadora; reciclar o arame desgastado; treine a mão-de-obra nas etapas de estocagem e secagem, para reduzir a porcentagem de produtos quebrados; aproveite o calor do forno para secagem artificial das telhas; incorpore resíduos de outros processos para a geração de calor, reduzindo o consumo da lenha; triture produtos quebrados e incorpore-os na massa cerâmica; fazer captura local do $\mathrm{CO}_{2}$, por meio de arborização na própria indústria e acondicionamento correto dos produtos na estocagem e expedição.

É importante ressaltar que, as sugestões de melhoria do processo produtivo visando a $\mathrm{P}+\mathrm{L}$ acima apresentadas devem ser analisadas e submetidas às demais etapas da metodologia que embasa o estudo, a fim de identificar quais destas são passives de implementação na empresa Alfa.

Por fim, é importante salientar que, embora o trabalho apresente como limitações o fato de ser um estudo de caso único, o qual não pode representar em totalidade o segmento de cerâmica vermelha, e apresentar uma visão limitada ao proprietário e gerente de produção sem considerar a opinião dos demais colaboradores, este estudo traz como contribuição ampliar a visão das empresas na busca pela preservação do meio ambiente, bem-estar social e uma produção eficiente, em especial no segmento estudado. Para tanto, sugere-se que trabalhos futuros sejam realizados como uma amostra representativa no segmento no país. 


\section{REFERÊNCIAS}

ABC - Associação Brasileira de Cerâmica. Cerâmica no Brasil: números do setor: cerâmica vermelha. 2003. Disponível em:

<http://www.abceram.org.br/asp/abc 283.asp.>. Acesso em: 20 mar. 2010.

BELKEL, R. V. Cleaner production and eco-efficiency initiatives in Western Australia 1996 - 2004. Journal of Cleaner Production, v. 15, n.1, p. 741-755, 2007.

BELKEL, R. V. Evolution and diversification of national cleaner production centres (NCPCs). Journal of Environmental Management, v. 91, n. 1, p. 1556 -565, 2010.

CEPIS - Centro de Produção Industrial Sustentável. Relatório de avaliação detalhada de produção mais limpa: cerâmica São Jorge. CEPIS: Campina Grande, 2008.

CNTL. Implementação de programas de produção mais limpa. Porto Alegre: CNTL - SENAI/RS, 2003(a). Disponível em: <http://www.senairs.org.br/cntl>. Acesso em: 18 abr. 2010.

. Cinco fases da implantação de técnicas de produção mais limpa. Porto Alegre: CNTL - SENAI/RS, 2003(b). Disponível em: <http://www.senairs.org.br/cntl>. Acesso em: 18 abr. 2010.

DONAIRE, Denis. Gestão ambiental na empresa. 2. ed. São Paulo: Atlas, 2007.

DRUNN, Kamila Camargo; GARCIA, Hugney Matos; UNIC, Floriano Peixoto. Desenvolvimento sustentável e gestão ambiental nas organizações. Revista científica eletrônica de ciências sociais aplicadas da EDUVALE, v. 1, n. 6, p. 111, 2011.

FRESNER, Johannes. Cleaner production as a means for affective environmental management. Journal of Environmental Management. London, v. 6, n.1, p. 171179, 1998.

GALKA, A. Using a cleaner production preventive strategy for the reduction of the negative environmental impacts of agricultural production-using cattle husbandry as a case study. Journal of Cleaner Production, v.12, n.1, p. 513-516, 2004.

GIL, Antonio Carlos. Como elaborar projetos de pesquisa. 3. ed. São Paulo: Atlas, 1996.

GIANNETTI, B., BONILLA, S., SILVA, I; ALMEIDA, C. Cleaner production practices in a medium size gold-plated jewelry company in Brazil: when little changes make the difference. Journal of Cleaner Production, v.16, n.1, p. 1106-1117, 2008. 
GRIGOLETTI, Giane de Campos; SATTLER, Miguel Aloysio. Estratégias ambientais para indústrias de cerâmica vermelha do Estado do Rio Grande do Sul. Ambiente Construído, Revista da ANTAC, v.3, n.3, p.19-32, 2003.

HUANG, Yi; LUO Jiwen; XIA Bin. Application of cleaner production as an important sustainable strategy in the ceramic tile plant e a case study in Guangzhou, China. Journal of Cleaner Production, v.43, n.1, p. 113 -121, 2013.

KIST, Lourdes Teresinha; MOUTAQI Said El; MACHADO, Ênio Leandro. Cleaner production in the management of water use at a poultry slaughterhouse of Vale do Taquari, Brazil: a case study. Journal of Cleaner Production, v.17, n.1, p. 1200 1205, 2009.

MARCONI, Marina de Andrade; LAKATOS, Eva Maria. Técnicas de Pesquisa: planejamento e execução de pesquisas, amostragens e técnicas de pesquisa, elaboração, análise e interpretação de dados. São Paulo: Atlas, 1999.

OLIVEIRA, João Fernando Gomes; ALVES, Salete Martins. Adequação ambiental dos processos usinagem utilizando Produção mais Limpa como estratégia de gestão ambiental. Produção, v. 17, n. 1, p. 129-138, 2007.

RBPML - Rede Brasileira de Produção mais Limpa. Guia da produção mais limpa: faça você mesmo. Disponível em: <http://www.pmaisl.com.br/publicacoes/guia-dapmaisl.pdf>. Acesso em: 22 abr. 2010.

SEBRAE - Serviço Brasileiro de Apoio às Micro e Pequenas Empresas. Cerâmica vermelha para construção: telhas, tijolos e tubos: estudos de mercado SEBRAE / ESPM, 2008. Disponível em: <http://www.biblioteca.sebrae.com.br/>. Acesso em: 28 abr. 2010.

SEVERO, Eliana Andrea; OLEA, Pelayo Munhoz. Metodologias de produção mais limpa: um estudo de caso no pólo metal-mecânico da serra gaúcha. INGEPRO Inovação, Gestão e Produção, v. 02, n. 6, p. 73-81, 2010.

SILVA, Gisele Cristina Sena da; MEDEIROS, Denise Dumke de. Metodologia de checkland aplicada à implementação da produção mais limpa em serviços. Gestão da Produção, v.13, n3, p.411-422, 2006.

SPERANDIO, Sérgio Antônio; GASPAR, Marcos Antônio. Gestão socioambiental em empresas industriais. Revista de Adm. UFSM, Santa Maria, v. 2, n. 1, p. 21-40, 2009.

TANAPONGPIPAT, A.; KHAMMAN, C.; PRUKSATHORM, K.; HUNSOM, M. ProcesS modification in the scouring process of textile industry. Journal of Cleaner

Production, v.16, n. 1, p. 152-158, 2008. 
VENDRAMETTO, Oduvaldo et al. Produção mais limpa: um movimento crescente em empresas brasileiras. Revista Produção online, v.10, n. 1, p. 49-70, 2010.

VILELA JÚNIOR, Alcir; DEMAJOROVIC, Jaques. Modelos e ferramentas de gestão ambiental: desafios e perspectivas para organizações. São Paulo: Senac, 2006 .

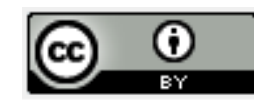

Artigo recebido em 24/07/2012 e aceito para publicação em 08/11/2013. 